\title{
Anti-Tumor Necrosis Factor Agents Are Mostly Used in Patients with Established Rheumatoid Arthritis Compared to Early Disease - A Reflection of Adequate Clinical Practice
}

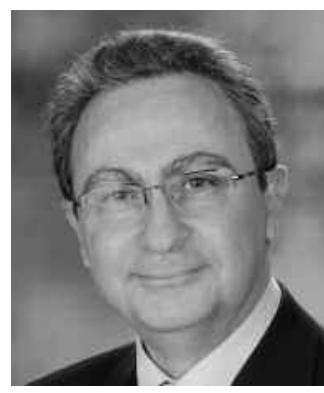

Almost 10 years after the introduction of the anti-tumor necrosis factor (TNF) agents for the treatment of rheumatoid arthritis (RA), rheumatologists are still struggling with their appropriate use and especially with the time to start them in the disease course. It is now well accepted that earlier disease control, i.e., suppression of inflammation, translates into better outcomes in terms of halting radiographic damage progression and preventing functional disability. Several clinical trials have shown the superiority of earlier use of combination methotrexate (MTX) and an anti-TNF agent ${ }^{1-3}$ compared to either agent used alone. However, given the cost of these new agents, economic considerations and the absence of predictive markers of response have prevented their use as first-line agents. Several national and international guidelines and consensus statements on the use of anti-TNF agents have been published ${ }^{4}$, the latest being the American College of Rheumatology recommendation document ${ }^{5}$.

Except for the European registries, which deal mostly with safety issues, there is little information on the practical use and effectiveness of anti-TNF agents, especially in early disease versus established RA. The article by Lee, et al from the CORONA database published in this issue sheds some light on this matter ${ }^{6}$ and as well raises several questions.

Should there be a difference between established and early RA in the use of anti-TNF agents? Based on the evidence that early is better, one would argue that over time we should see more patients with shorter disease duration using anti-TNF agents. This assumption is not supported by their findings. And this raises the larger issue of appropriate optimal treatment of RA. We have learned over recent years to better use our traditional disease modifying antirheumatic drugs (DMARD) and to treat to a target of remission or at least low disease activity assessed by validated composite measures $^{7-9}$. Therefore patients who do not achieve these goals should be treated with anti-TNF agents regardless of their disease duration. Indeed, we can see that in the
CORONA database, the level of disease activity at the time of the introduction of biologic agents was the same in both early and established disease groups and was therefore probably the main reason for therapy modification.

If the therapeutic target is the same regardless of disease duration, why are we seeing more use of anti-TNF agents in established disease? One might speculate that based on current recommendations, anti-TNF agents are introduced only after the failure of MTX alone or in combination with other traditional DMARD. For instance, when analyzed more carefully, only $20 \%$ of the patients in the step-up strategy of the BeSt trial (Arm 2) fail to achieve low disease activity after triple combination of MTX, hydroxychloroquine, and sulfasalazine; and less than $10 \%$ fail this triple combination plus low-dose corticosteroids after 2 years ${ }^{10}$. If this strategy best represents our current approach to the treatment of $\mathrm{RA}$, it is not surprising to see that a minority of patients will require anti-TNF agents in the first 2 years of their disease. We have also learned that retention of traditional DMARD is reduced over time because of secondary loss of efficacy or tolerability/toxicity issues. This contributes to a higher number of later introductions of anti-TNF agents.

How many patients, in real-life practice, require anti-TNF therapy? The CORONA database has the highest percentage $(35 \%)$ of patients with RA ever reported to be treated with an anti-TNF drug. In European registries the average varies between $8 \%$ and $20 \%$. The difference is mainly due to a lower threshold of disease activity at the start of a biologic agent in the CORONA database [Disease Activity Score 28 (DAS28) 2.9 to 5.7] compared to other registries: for instance, a Swedish registry (DAS28 5.5 to 5.9), the Dutch DREAM (DAS28 5.2 to 5.5), or the Danish DANBIO (DAS28 decreasing over time from 5.9 to $5.3)^{11-13}$. Several factors may contribute to this difference: On the one hand there is easier access to biologics based on more relaxed guidelines or reimbursement coverage and patients' demands and expectations; on the other, there are

See Utilization trends of TNF inhibitors in US patients with RA, page 1611 
negative factors such as patient concerns regarding side effects and toxicities. All these factors are difficult to tease out from observational studies or registries. When only patients with early RA are considered, 16\% of patients followed in the SSATG registry required anti-TNF agents in the first 2 years of disease, which is probably slightly lower than the $25 \%$ after 3 years observed in the CORONA database $^{14}$.

This raises the more delicate and controversial question of cost versus benefit. Despite short-term studies and modelization of cost that support use of anti-TNF agents in moderate to severely active disease despite adequate traditional DMARD, longterm data on true direct (hospitalization, reduction of comorbidities, joint replacements, drug toxicities...) and indirect costs (work and out-of-work productivity) are needed to settle this issue once and for all.

With the advent of new classes of biologic agents directed against several other cellular and cytokine targets, there is a large unmet need for developing a rational approach to the treatment of RA that is not solely based on empiricism. Research should focus on predictive markers of response to different therapeutic agents, to use the best drug in the most appropriate patient. In the meantime, the best approach is to treat early with a target of remission/low disease activity by rapid optimization of traditional DMARD and prompt introduction of a biologic agent in those patients who fail to achieve the preset goal.

BOULOS HARAOUI, MD, FRCPC, Associate Professor of Medicine, Université de Montréal, Montreal, Quebec, Canada

Address correspondence to Dr. B. Haraoui, CHUM, Campus Notre-Dame, 1560 Sherbrooke est, Montreal, Quebec H2L 1 S6.

E-mail:bharaoui@videotron.ca

\section{REFERENCES}

1. St. Clair EW, van der Heijde DMFM, Smolen JS, et al. Combination of infliximab and methotrexate therapy for early rheumatoid arthritis. Arthritis Rheum 2004;50:3432-43.

2. Klareskog L, van der Heijde D, de Jager JP, et al. Therapeutic effect of the combination of etanercept and methotrexate compared with each treatment alone in patients with rheumatoid arthritis: double blind randomized controlled trial. Lancet 2004;363:675-81.

3. Breedveld FC, Weisman MH, Kavanaugh AF, et al. The PREMIER study: A multicenter, randomized, double blind clinical trial of combination therapy with adalimumab plus methotrexate versus methotrexate alone or adalimumab alone in patients with early aggressive rheumatoid arthritis who had not had previous methotrexate treatment. Arthritis Rheum 2006;54:26-37.

4. Lopez-Olivo MA, Kallen MA, Ortiz Z, Skidmore B, Suarez-Almazor ME. Quality appraisal of clinical practice guidelines and consensus statements on the use of biologic agents in rheumatoid arthritis: a systematic review. Arthritis Rheum 2008;59:1625-38

5. Saag K, Teng GG, Patkar NM, et al. American College of Rheumatology 2008 recommendations for the use of non-biologic and biologic disease modifying antirheumatic drugs in rheumatoid arthritis. Arthritis Rheum 2008;59:762-84.

6. Lee SJ, Chang H, Yazici Y, Greenberg JD, Kremer JL, Kavanaugh A. Utilization trends of tumor necrosis factor inhibitors among rheumatoid arthritis patients in a United States observational cohort Study. J Rheumatol 2009;36:1611-7.

7. Grigor C, Capell H, Stirling A, et al. Effect of a treatment strategy of tight control for rheumatoid arthritis (the TICORA study): a single blind randomised controlled trial. Lancet 2004;364:263-9.

8. Goekoop-Ruiterman YPM, de Vries-Bouwstra JK, Allaart CF, et al. Clinical and radiographic outcomes of four different treatment strategies in patients with early rheumatoid arthritis (the BeSt Study). Arthritis Rheum 2005;52:3381-90.

9. Verstappen SMM, Jacobs JWG, van der Veen MJ, et al. Intensive treatment with methotrexate in early rheumatoid arthritis: aiming for remission. Computer assisted management in early rheumatoid arthritis (CAMERA, an open-label strategy trial). Ann Rheum Dis 2007;66:1443-9.

10. van der Kooij SM, de Vries-Bouwstra JK, Goekoop-Ruiterman YPM, et al. Limited efficacy of conventional DMARDs after initial methotrexate failure in patients with recent onset rheumatoid arthritis treated according to the Disease Activity Score. Ann Rheum Dis 2007;66:1356-62.

11. Kristensen LE, Saxne T, Nilsson JA, Geborek P. Impact of concomitant DMARD therapy on adherence to treatment with etanercept and infliximab in rheumatoid arthritis. Results from a six-year observational study in southern Sweden. Arthritis Res Ther 2006;8:R174.

12. Kievit W, Adang EM, Fransen J, et al. The effectiveness and medication cost of three anti-tumour necrosis factor alpha agents in the treatment of rheumatoid arthritis from prospective clinical practice data. Ann Rheum Dis 2006;67:1229-34.

13. Hetland ML, Lindegaard HM, Hansen A, et al. Do changes in prescription practice in patients with rheumatoid arthritis treated with biological agents affect treatment response and adherence to therapy? Results form the nationwide Danish DANBIO registry. Ann Rheum Dis 2008;67:1023-6.

14. Soderlin MK, Geborek P. Changing pattern in the prescription of biological treatment in rheumatoid arthritis. A 7-year follow-up of 1839 patients in southern Sweden. Ann Rheum Dis 2008;67:37-42.

J Rheumatol 2009;36:1561-2; doi:10.3899/jrheum.090594 